\title{
ADAPTACIÓN Y DRAMATURGIA EN DOS OBRAS DE AGUSTÍN MORETO
}

Patricia Trapero

Universitat de les Illes Balears

Si observamos la sección teatral del siglo XVII en cualquier manual de «Historia de la Literatura Española» veremos cómo se nos habla de unas condiciones políticas, sociales y económicas que marcarán la aparición de unos elementos referenciales en el desarrollo del arte escénico de la época, cuyo centro se sitúa siempre en la figura del escritor Lope de Vega.

Así, asistimos a una división periódica que, normalmente fragmenta el siglo que nos ocupa en dos grandes figuras, ciclos o «escuelas» (la de Lope y la de Calderón) con características propias que son, casi con exclusividad, el hecho de la configuración de un esquema modélico para la escritura de las obras y la representación de las comedias y, en segundo lugar, una superación de este esquema tendente a un perfeccionamiento estético y conceptual. Sin embargo, esta visión excesivamente taxonómica de un período tan complejo respecto al fenómeno teatral deja de lado dos hechos básicos:

a) las constantes interferencias de unos autores con otros que demuestran la inoperancia o relatividad de la división cíclica mencionada. Así, las polémicas téricas y prácticas acerca de la escritura dramática van a ser factores de modificación respecto a estos postulados aparentemente inamovibles;

b) el hecho de que existe una distinta conciencia estética respecto a lo que es el planteamiento de la originalidad y el bagaje cultural que compartirán los autores de ambos ciclos $(\mathrm{y}$, evidentemente, autores anteriores o 
posteriores en el tiempo) y que muestran una especie de continuidad en los presupuestos dramáticos.

De esta manera, van a aparecer modalidades dramatúrgicas consistentes en la reelaboración, con técnicas compartidas, de materiales diversos que configurarán el Siglo de Oro español como una época en que la escritura dramática va a tener formas diversas y que deben ser estudiadas. Nos referimos a la llamada «técnica de la refundición» de la que Agustín Moreto es el representante «oficialmente reconocido como tal» (si se nos permite la expresión) por todos los historiadores de la literatura dramática española.

Poco sabemos acerca de Agustín Moreto y Cabaña (1619-1669), calificado como "el mejor de los discipulos de Calderón " 1 . Moreto nace en Madrid el 8 de abril de 1619 en el seno de una familia acomodada de origen italiano; estudia lógica y física en Alcalá recibiendo las órdenes menores y desarrollando su actividad en la capital, probablemente en un ambiente cortesano; morirá el 28 de octubre de 1669.

Su producción dramática ha sido dividida de modo general en distintos epígrafes ${ }^{2}$ si bien todos coinciden en apuntar ${ }^{3}$ la importancia, para entender la obra de Moreto, del análisis de su actitud ante el teatro: de hecho, un elevado porcentaje de las piezas de este autor son reelaboraciones de textos de otros dramaturgos. La fama de Moreto se debe, pues, a una actitud de actualización de obras anteriores:

Y en medio de este peligro, reparé que don Agustín Moreto estaba sentado y revolviendo unos papeles que, a mi parecer, eran comedias antiquísimas, de quien nadie se acordaba. Estaba diciendo entre sí: «Esta no vale nada. De aquí se puede sacar algo, mudándole algo este paso puede aprovechar» Enojeme de verle con aquella flema cuando todos estaban con las armas en las manos. Y díjele que ¿por qué no iba a pelear como los demás? A qué me respondio: «Yo peleo aquí más que ninguno, porque aquí estoy minando al enemigowVuesa merced, le repliqué, me parece que está buscando qué tomar de esas comedias viejas». «Eso mismo (me respondió) me obliga a decir que estoy minando al enemigo: y échelo de ver en estas coplas

1 WiLsON, E.M. y MOIR, D.: Siglo de Oro: teatro vol. 3 de la Historia de la literatura española, Ariel, Barcelona, 1979 (3 ed.) pág. 199.

2 Ver al respecto la división de FERNÁNDEZ GUERRA, LuIS. Introducción a las Obras escogidas de Don Agustín Moreto y Cabaña, BAE, Madrid, 1865.

3 Entre otros, F. RUIz RAMÓN Historia del teatro español I. Desde sus origenes hasta 1900 (Alianza ed. Madrid 1971) y J.M. DIEZ-BORQUE, El teatro del siglo XVII, Taurus, Madrid, 1988. 
Que estoy minando imagina

cuando tú de mi te quejas;

que en estas comedias viejas

he hallado una brava minan 4

No cabe duda de que las inevitables palabras leídas por Jerónimo de Cáncer y Velasco en su Vejamen literario de 1640 ante la Academia de Madrid referidas al trabajo dramatúrgico de Agustín Moreto han configurado una corriente de opinión entre los estudiosos del teatro aúreo donde se acusa al autor de plagio, opinión tan sólo subsanada por la valoración de sus obras originales, principalmente El desdén con el desdén y El lindo Don Diego. La acusación de plagio ha sido, pues, la tónica dominante en la consideración del trabajo de Moreto.

Sin embargo, los trabajos de R. L. Kennedy, B. Wardropper, E. Caldera, J. A. Castañeda y F. Casa ${ }^{5}$ sobre el autor, han puesto de manifiesto el hecho de que los dramaturgos del siglo XVII operan desde una optica diferente a la actual respecto a los principios artísticos a los que no será ajeno Moreto de cuya labor, inconscientemente, el propio Cáncer y Velasco nos ofrece un punto de partida. La acusación de «imitación servil» o de "plagio» es inexacta ya que en el período que nos ocupa se entendía la originalidad en muy distinto sentido. Tal como señala acertadamente J. L. Alborg. ${ }^{6}$

El plagio - por decirlo brevemente con una palabra más crudaera una necesidad a que apremiaban mil circustancias. El dramaturgo, desde Calderón al más adocenado, trabajaba de encargo infinitas veces; no es el problema, entiendase, de codicia o de cuquería, sino que había de atender demandas inexcusables, con frecuencia del mismo monarca, o de políticos eminentes, o de hermandades o corporaciones que precisaban un «auto» o una comedia para determinada festividad; y entonces quedaba escaso tiempo para exigirle novedades al propio genio; alli estaba el caudal dramático derrochado precipitademente por muchas docenas de colegas.

4 CÁNCER y Velasco, J., Vejúmenes literarios en A. Bonilla y SAN MARTin (ed.), Oro viejo, Madrid, 1909.

5 KENNEDY, R.L., The dramatic art of Moreto, Philadelphia, 1932; WARDROPPER, B.W., *El desdén con el desden : the comedia secularized, Bulletin of Hispanic Studies XXXIV, 1957, págs. 1-9; Caldera, E., Il teatro di Moreto, Librería Goliardica, Pisa 1960; CASTAÑEDA, J.A. Agustin Moreto. Twayne, New York, 1974 y CASA, F. The dramatic craftsmanship of Moreto, Harvard UP, Mass., 1966.

6 Alborg, J.L. Historia de la literatura española, t. II, Gredos, Madrid, 1970 (2 ed.) pág. 878. 
La llamada «refundición» es un fenómeno bastante frecuente entre nuestros dramaturgos del Siglo de Oro. La base de la costumbre de la imitación de otras obras fue avanzada por Cicerón ${ }^{7}$ como práctica habitual regulada por los artistas de manera que las obras escritas pertenecen a la comunidad social y pueden ser utilizadas por ella; los modelos deben ser elegidos, estudiados minuciosamente e imitados siempre y cuando el autor siga su modelo. Todas estas consideraciones se desarrollarán ampliamente en el Renacimiento ${ }^{8}$, momento en que los artistas poseen la noción de que el conocimiento no pertenece a un individuo particular sino que el poder de ideas es comunitario, la temática es un patrimonio social que puede ser utilizado de manera libre y cuya única finalidad consiste en la superación estética de las fuentes. La idea de que la perfección puede lograrse con la remodelación estricta de materiales preexistentes potenciará el fenómeno de la refunción.

$\mathrm{El}$ «caso Moreto» no es más que una muestra de una práctica dramatúrgica que se potenciará especialmente entre los autores del ciclo calderoniano en el que la perfección prima sobre la creación. Poco importa cuál fuere la causa de los plagios de Moreto ya que nos encontramos ante un autor con una gran habilidad dramática en la técnica refundidora.

Moreto was not a creator of original plots, he used what was available to him and he owes a great deal to his predecessors. His worth lies not in this secondary aspect of creation but in the more important one of execution. In this Moreto shows himself to be a "consumate craftsmanm: the development of his plots, the characterization of his personages, and the conclusion of his plays all evidence complete control of material ${ }^{9}$

El material utilizado por Moreto para sus obras, tal como hemos señalado, va a ser, en un porcentaje elevadísimo, de procedencia ajena; sin embargo sus textos son re-creaciones dramáticas y no meros depósitos de testimonios sobre reminiscencias temáticas de obras anteriores. $Y$ hablamos de re-creaciones en Moreto porque si trasladamos la idea de la refundición a los términos de la teatrología, no cabe duda de que la labor de nuestro autor es doble: la adaptación y el trabajo dramatúrgico.

7 De oratore II, 90. También será así en Horacio (Ars. Poética II, 128-135) y Quintiliano (De institutione oratorio $\mathrm{X}, \mathrm{II})$.

8 Bullock, Walter L. The precept of plagiarism in the Cinquecento, Modern Philology XX, 1928, pp. 293-312.

9 CASA, F. op. cit., pág. 5. 
La adaptación tiene básicamente dos acepciones. Una es la de transformación de una obra de un género literario en otro que, por lo general, consiste en un cambio de contenidos épico-narrativos en contenidos dramáticos; la otra consiste en el trabajo sobre un texto ya destinado a la puesta en escena donde cualquier maniobra textual se permite ${ }^{10}$. Si el concepto de adaptación va a llevar implícito el estudio de la teatralidad de una obra no dramática, en la dramaturgia deberemos ver, siguiendo su sentido original, el «arte de la composición de las obras de teatro» ya que intenta establecer los principios de construcción de la obra, bien inductivamente a partir de ejemplos concretos, bien deductivamente a partir de un sistema de principios abstractos ${ }^{11}$.

Debe ser en estos parámetros donde debemos situar el fenómeno de las refundiciones del teatro aúreo. Tal como afirma J. Weiger ${ }^{12}$, la originalidad en este período excluye la consideración de «novedad»: la originalidad no consistirá en la novedad del argumento sino en el ingenio de la construcción interna respecto a un paradigma (una dramaturgia, la lopesca) popularmente aceptado. De hecho, dentro de toda consideración dramatúrgica existen dos tipos de estructuras: la interna o partes constituyentes del sistema dramático que se organizan para producir un sentido global, y la externa relacionada con la presentación del texto, en el caso del XVII el argumento.

En definitiva, el autor refundidor del siglo XVII va a verse constreñido por el patrón lopesco al que puede seguir o del que se puede desviar. Agustín Moreto seguirá también en buena parte de su trabajo refundidor estos esquemas paradigmáticos pero con una actualización crítica en el afán de creación de «un universo dramático nuevo, contando con lo anterior» ${ }^{13}$ que lo convierte, desde nuestro punto de vista, en la perfecta combinación de las dos grandes escuelas del XVII, tal como veremos en el análisis de dos de sus piezas: El Parecido en la Corte y El Licenciado Vidriera.

10 Las maniobras textuales para la adaptación de un texto han sido discutidas por autores y directores. Buena muestra del trabajo dramatúrgico y de adaptación lo tenemos en Bertolt Brecht: La vida del rey Eduardo II de Inglaterra (Marlowe), Coriolano (Shakespeare), Antigona (Sofocles) - Don Juan (Molière).

11 No cabe duda de que, en nuestro caso, la referencia obligada dramatúrgicamente hablando es el Arte Nuevo de hacer comedias en este tiempo, de Lope de Vega.

12 WEIGER, J. La *comedia nueva*. Una vez más sobre el juego de la originalidad. Cuadernos de Teatro Clásico I, 1988, pp. 11-25.

13 Ruiz RaMón, op. cit. pág. 309. 
Debemos situar la obra de Moreto El Parecido en la corte (1650-1652) dentro de los que hemos denominado trabajo dramatúrgico, consistente en la reelaboración de un material dramático preexistente o coetáneo al refundidor. En el caso que nos ocupa, varias son las fuentes que se han señalado para la obra moretiana:

1. El castigo del penséque de Tirso de Molina ( 1613 o 1614) ${ }^{14}$;

2. La Entretenida de Miguel de Cervantes $(1615)^{15}$ y

3. La villana de Vallecas de Tirso de Molina $(1620)^{16}$.

Si prestamos atención a las posibles fuentes de la obra de Moreto, éstas se concentran en dos autores, Cervantes y Tirso; sin embargo, el trasfondo de ambos, así como de todos los autores dramáticos del XVII, es la figura de Lope de Vega. De hecho, la fecha 1613-1614 marca el inicio de la polémica surgida con la aparición del tratado lopesco El Arte Nuevo de hacer comedias en este tiempo (1609).

En estas coordenadas hemos de enmarcar la redacción de La Entretenida, obra ambigua donde, según todos los estudiosos ${ }^{17}$, Cervantes parodia los textos de su rival si bien con la utilización de una estructura, temas y personajes según la fórmula lopesca pero con un desarrollo original y la disposición final de criticar los defectos de la misma. Por otro lado, la aparición del tratado lopesco conlleva las figuras de los detractores y defensores entre los que se encuentra su acérrimo paladín Tirso de Molina quien escribirá en favor de su maestro la obra Los cigarrales de Toledo (1620-1624). Del mismo modo en que Cervantes atacaba a Lope, supuestamente, en La Entretenida, Tirso satirizará a aquél en todas sus obras, también en El castigo del penséque, verdadero desagravio de los ataques cervantinos a Lope y al propio Tirso y donde encontraremos constantes alusiones al autor del Quijote.

14 DfEZ-BORQUE, J.M., Historia del teatro español, vol. I, Taurus, Madrid, 1983, pág. 593.

15 PERIS MENChetA, J.S., Ensayo de una bibliografia de miscelánea cervantina. Comedias, historietas, novelas, poemas, zarzuelas, etc., inspiradas en Cervantes o en sus obras. Barcelona 1947, pág. 10 y GARCIA MARTIN, M. Cervantes y la comedia española del siglo, XVII, Universidad de Salamanca, 1980.

16 Garcia Martin, op. cit.

17 Ver al respecto los trabajos de ZIMIC, S. Cervantes frente a Lope y la comedia nueva (Observaciones sobre La Entretenida) Anales Cervantinos IV, 1976, págs. 19-119; FLECNIAKOSKA, J.L. Quelques propos sur ala comedia famosa de La Entretenida, Anales Cervantinos XI, 1972, págs. 17-32 y AVAlle-ARCE, J.B. On La Entretenida, Modern Language Notes, 1959, págs. 418-421. 
Así, dos de las obras que ocupan nuestra reflexión sobre el trabajo dramatúrgico de Agustín Moreto se encuentran inmersas en la polémica suscitada por el paradigma teatral de Lope que condicionará la temática de las cuatro piezas mencionadas del mismo modo que en su grado de seguimiento, transgresión y originalidad respecto a las llamadas «comedias de enredo» 0 "comedias de capa y espada» 18 .

Las cuatro obras responden a una temática común, constántemente repetida en las comedias de capa y espada, que es el concepto de la «ficcionalidad de la personalidad" y que condicionará el desarrollo de la obra. Esta temática corresponde al enunciado de A.Valbuena Briones para la comedia de capa y espada calderoniana ${ }^{19}$.

... Los sentidos son engañosos, las cosas no son como parecen. EI oído y la vista causan confusiones y trastornos. La razón de los protagonistas se enfrenta con experiencias desconcertantes. La firme y optimista facultad de captar la realidad, evidente en el Renacimiento, se ha resquebrajado en un juego de luz y sombras que no permite distinguir con acierto. Las evidencias aparentes enmascaran la realidad, crean desdoblamientos de identidades, conducen por líneas retorcidas y soprendentes a un laberinto (...) verdad y mentira pueden coincidir simultáneamente.

Sin embargo, cada una de ellas va a plantear de modo distinto esta ficcionalidad de la personalidad, atendiendo a su argumento y a la complicación de su estructura y personajes.

1. El castigo del penséque va a tratar el tema del parecido físico como desencadenante de las confusiones que plasmará en el enredo, no se produce una suplantación de personalidad sino que una tercera persona se confunde y provoca el argumento: Don Rodrigo Giron va a ser confundido con Otón.

2. La Entretenida va a tratar el tema de dos maneras distintas. En primer lugar va a haber una suplantación de personalidad (Cardenio se hace pasar por Don Silvestre de Armendárez) y, en segundo lugar, hay una confusión en la personalidad por la existencia de dos personas idénticas (Marcela Osorio y Marcela Armendárez). Este último planteamiento irá ligado al tema del incesto, segundo tema de la obra.

18 Para sus características ver el trabajo de ARELLANO, I., Convenciones y rasgos genéricos en la comedia de capa y espada, Cuademos de teatro clásico 1, 1988, págs. 27-50.

19 En Calderón y la comedia nueva. Espasa-Calpe. Madrid 1977, págs. 46-47. 
3. La villana de Vallecas va a tratar dos cambios de personalidad, una, fortuita por un objeto, una maleta (que el propio Moreto reelaborará en su obra La ocasión hace al ladrón y el trueque de las maletas, anterior a 1676) protagonizada por Don Pedro de Mendoza y Don Gabriel de Herrera. La otra, voluntario, protagonizada por Doña Violante que, sucesivamente, va adoptando distintas personalidades para poder llevar a cabo la restauración de su honor.

4. El Parecido en la corte es una combinación de aspectos de cada una de las obras precedentes. De este modo, va a aprovechar de El castigo del penséque la confusión a través de una tercera persona (Don Fernando de Ribera será Don Lope de Luján); La Entretenida va a proporcionar a Moreto algún momento de la similitud física de las dos personas ${ }^{20}$. Finalmente, de La villana de Vallecas tomará el hecho de que ningún personaje creerá la confesión de la personalidad, produciéndose las situaciones cómicas. El tipo de la suplantación femenina por reparación del honor se da en Moreto sólo como un juego (Doña Ana y Doña Inés).

Así, hallamos variantes en el tema de la ficcionalidad en todos los autores si bien todos responden al esquema de la verosimilitud de las situaciones presentadas en el desarrollo argumental. El mecanismo que van a utilizar de manera conjunta va a ser el del «engaño ante los ojos» donde, a partir de situaciones (principalmente en Tirso y Moreto) o discursos ambiguos (en Cervantes y en Moreto referidos al incesto) los personajes creerán que se plantea un conflicto donde en realidad no existe.

Tanto Tirso como Cervantes y Moreto siguen las indicaciones que Lope propusiera en su Arte Nuevo en los versos 323-326

Siempre el hablar equivoco ha tenido
y aquella incertidumbre anfibológica,
gran lugar en el vulgo, porque piensa,
que él solo entiende lo que el otro dice.

De tal manera que esta técnica confiere al espectador un punto de vista privilegiado y con él una información mejor que la obtenida por los actores o personajes en escena respecto a los cuales el público experimenta una sensación de superioridad al tiempo que se produce una complicidad entre el autor omnisciente y el público que lee o contempla la obra, no así entre los personajes. Se da, pues, una forma de «teatro dentro del teatro» donde el plameamiento

20 Que también encontramos en El castigo del penséque aunque tanto en Tirso como en Moreto la similitud es aparente mientras que en Cervantes es real ya que hay dos Marcelas. 
de que «la verosimilitud del suceso no se halla en referencia a la posibilidad de los hechos sino a la razón última de verdad con independencia del contenido de las acciones» 21 va a ser seguido por Tirso en las dos obras y modificado por Cervantes y, en parte, por Moreto quienes sustituirán el contenido de las acciones por el contenido de las opiniones o pensamientos de los personajes (aunque también se dé en el personaje de Clavela de El castigo del penséque).

Este último aspecto debe ligarse de manera concreta al segundo tema común de tres de las obras (ya que no se da en La villana de Vallecas) que nos ocupan: el tema del incesto.

1. El castigo del penséque presenta una relación incestuosa entre el supuesto Otón y su hermana Clavela, sin embargo, esta relación es esbozada por Tirso y, desde nuestro punto de vista, es útil para la caracterización de los personajes: los celos de los personajes femeninos y la configuración del prototipo del "penséque» que acerca la obra de Tirso al esquema de la comedia de figurón.

2. La Entretenida es la obra que presenta una mayor complicación en el tema del incesto. La relación incestuosa entre Don Antonio y su hermana real (ya que en Tirso y Moreto no lo son) es inexistente al crearse en la mente del personaje femenino que considera inverosimil la posible existencia de una sosías; se da, pues, un conflicto entre la ficción o imaginación de un personaje y la realidad contextual de la obra.

Cervantes va a conferir al personaje, a través de este tema, un elemento de fluctuación de pensamiento que no responde al típico esquema teatral de acción/reacción ante el estímulo del conflicto dramático (cosa que sí sucederá en Tirso y en Moreto) sino al del punto de vista del personaje femenino.

3. El Parecido en la corte va a recoger, en nuestra opinión, el esquema cervantino modificándolo. Si Tirso caracterizaba en su obra al penséque sin que el tema de la ficcionalidad de la personalidad y el incesto se unieran, Moreto va a juntar los dos bloques temáticos a través de un mecanismo cómico que proporcionará al galán la posibilidad de una actividad amatoria (inmersa de lleno en los presupuestos lopescos) dando verosimilitud a las acciones del suplantador ante su amada. Nos referimos a la amnesia como elemento que transformará en natural la relación incestuosa: un recurso de unión entre ambos temas que no se da en ninguna de las obras que nos ocupan.

De este modo, pensamos que la propuesta de Moreto se aproxima más a la cervantina en cuanto al planteamiento de puntos de vista de los personajes que a la tirsiana de la que calcará situaciones previas.

21 Como define J.M. DIEz-BORQUE en Teatro dentro del teatro, novela de la novela en Miguel de Cervantes, Anales Cervantinos xv, 1972, pg. 113. 
Hemos visto hasta el momento cómo el amor es el centro de los argumentos de todas las comedias de capa y espada (y del sistema conceptual lopesco). Este se va a plasmar dramáticamente a través de una serie de relaciones individuales y sociales ente los personajes ${ }^{22}$. Es evidente que en todos los textos que analizamos se dan una serie de juegos amorosos entre los personajes cuya complicación aumenta según el grado de desarrollo del enredo o maraña por parte del autor.

De este modo, las relaciones amorosas de cada una de las obras pueden ser esquematizadas así:

El castigo del penséque

NIVEL A

(1) Don Rodrigo - Clavela - Diana

(2) Don Rodrigo - Clavela - Pinabel

(3) Don Rodrigo- Diana- Casimiro

NIVEL B

Lucrecia - Chinchilla

La Entretenida

NIVEL A

(1) Don Silvestre - Marcela Armendárez - Cardenio

(2) Don Silvestre - Don Antonio- Cardenio- Marcela Osorio

(3) Don Antonio - Marcela Osorio - Don Ambrosio

NIVEL B

Quiñones - Torrente - Ocaña - Cristina

La villana de Vallecas

(1) Don Gabriel - Doña Violante - Doña Serafina

(2) Don Gabriel - Don Pedro - Doña Serafina

(3) Teresa/Violante - Don Juan

(4) Incidencia de Don Vicente y Don Luis

El Parecido en la corte

NIVEL A

Doña Inés Don Fernando - Don Diego

NIVEL A'

Don Lope - Doña Ana

NIVEL $B$

Tacón - Leonor

Estos esquemas relacionales ponen en evidencia, a nuestro parecer, la considerable reducción de la complicación del enredo en el caso de Moreto que va

22 Seguimos la aportación de J.M. DfEZ-BORQuE Sociología de la comedia española del siglo XVII. Cátedra. Madrid, 1976. 
a concentrarlo en los pasos de la consolidación de la casuística amorosa del personaje de Inés.

En las obras de Tirso y Moreto se da el planteamiento del amor súbito, característica del paradigma lopesco, no así en el texto de Cervantes quien nos presenta a los personajes masculinos «ya» enamorados y cuyo planteamiento argumental presupone una serie de situaciones amorosas previas al desarrollo en escena convirtiéndolas en esbozos de relaciones argumentales no explicadas; en definitiva, Cervantes presenta expectativas dramáticas, normalmente inmersas en los esquemas lopescos, que convierten La Entretenida en una obra «abierta» a una recepción supratextual inicialmente acorde con los esquemas dramáticos aceptados popularmente. De hecho, algunas de estas expectativas dramáticas (concretamente las relaciones padre-hija) van a ser extraídas por Moreto del texto cervantino.

El amor es también presentado en la comedia del siglo XVII como una pasión irracional que anula cualquier actividad humana diferente a él, se sitúa por encima de toda contingencia espiritual y material consiguiendo la transformación de las almas y siendo el motor de la acción. La enajenación amorosa se manifiesta a través de los parlamentos (monólogos y diálogos) y a través de la acción, ya que amar presupone una actividad.

Justamente van a ser los personajes femeninos en las obras que nos ocupan las que van a sobresalir bien por sus actuaciones (Violante en La villana de Vallecas o Marcela Osorio en La Entretenida) bien por la evolución de su psicología (Clavela en El castigo del penséque e Inés en el texto de Moreto) de tal manera que, mientras los galanes ${ }^{23}$ actúan con diferentes comportamientos -teatralmente (Don Antonio de Armendárez o Don Ambrosio), seductoramente (Don Fernando de Ribera) o fluctuantemente (Don Rodrigo Girón)- las damas van a ser las que van a ejercer el desarrollo de la acción. No es extraño, pues, que Moreto tomara las obras de Tirso y Cervantes como fuentes para su trabajo dramatúrgico.

En definitiva, es evidente el trabajo de refundición de Moreto (que, realmente, funde los argumentos de tres obras en una propia) cuyas características se centran en el poder de condensación y de reducción de elementos superfluos

23 No nos ocupamos del resto de los dramatis personae ya que nuestro propósito es ver la originalidad de Moreto en los planteamientos argumentales. De todas formas, en las obras que nos ocupan se reflejan todos los actantes del modelo lopesco aparte de los galanes y damas ya mencionados: criados (Chinchilla, Luzón, Torrente y Tacón) y criadas (Lucrecia y Leonor). Mención aparte merece el texto cervantino donde la subversión del esquema lopesco alcanza a los personajes que ya no son actantes; así, encontramos antigalanes (Cardenio), pseudogalanes (Don Antonio y Don Silvestre), anticriadas (Cristina), antigraciosos (Ocaña) y pseudodamas (Marcela Armendárez). 
en una coherencia estructural patente: cada una de las partes de El Parecido en la corte es esencial y eslabonadas unas con otras de manera que, si se suprimiera alguna de ellas, se derribaría la trama. En este caso, es cierta la afirmación de Fernández Guerra ${ }^{24}$ de que

pocos de sus contemporáneos tienen tantas comedias que se puedan poner hoy en escena sin necesidad de alterarlas ni refundirlas. Débese esto al delicado gusto $e$ insigne constancia con que, renunciando a la nombradía de original y fecundo, gozó en desarrollar, completar y perfeccionar lo que era digno de complemento y mejora, sabiendo que sin la forma el pensamiento no vive. Así jamás ni su gloria ni su provecho le interesaron tanto como la gloria y el provecho del arte.

\section{LA ADAPTACIÓN EL LICENCIADO VIDRIERA}

El Licenciado Vidriera de Agustín Moreto aparece publicada en 1676 en la Segunda parte, primera edición de sus obras juntamente con El Parecido en la corte, entre otros textos. La filiación cervantina del texto de Moreto es evidente en el propio título de la obra, pero también es explicitada por el autor en las palabras pronunciadas por el personaje de Gerundio al acabar la obra
$\mathrm{Y}$ aquí, discreto Senado, se da, con vítores vuestros
fin dichoso al Licenciado
Vidriera, sin novela
y las fortunas de Carlos.

Si en el apartado anterior hemos reflexionado acerca del trabajo dramatúrgico de Moreto, ahora vamos a referirnos a su técnica adaptadora en la transformación de una obra no dramática a unos mecanismos del lenguaje teatral. Así, la primera cuestión que debemos plantear es si la novela ejemplar cervantina como material narrativo contiene elementos teatrales que den pie a una elaboración dramática de la misma; en definitiva, hemos de constatar el grado de teatralidad de la novela o la posible existencia de matrices teatrales en ella.

\footnotetext{
24 Op.cit. pg. xxviii.
} 
De entre las propuestas de teatralidad aportadas por la semiótica teatral ${ }^{25}$ es la del espacio la que, desde nuestro punto de vista, va a poder aplicarse al texto de Moreto. En la división espacial de la teatrología, se suele distinguir el espacio dramático como opuesto al escénico, cuya característica principal es que el primero es construido por el espectador para fijar el cuadro de la evolución de la acción y de los personajes y que pertenece al texto dramático. De esta manera se afirma ${ }^{26}$ que los modelos históricos y lingüísticos del espacio se convierten en la base de la construcción de una «imagen del mundo» y un modelo ideológico propios de una determinada cultura.

Teatralmente hablando, estas consideraciones van a traducirse en la aparición, en toda obra dramática, de dos espacios (o zonas de significación) en conflicto que se definen por su relación respectiva, pero cuyos elementos no sólo son espaciales o espacializables sino que en ellos se puede determinar lo esencial de la acción dramática según las modificaciones en las relaciones de cada uno de sus elementos. Así, los dos espacios en conflicto mantienen una relación dinámica entre ellos.

En el caso de El Licenciado Vidriera cervantino (cuyo argumento es conocido por todos) los dos espacios en conflicto son el individuo y la sociedad, tema, por otro lado, eminentemente teatral al reproducir conflictos entre los seres humanos. La novela ejemplar cervantina plantea una parte del esquema de los componentes normalmente asignados al desarrollo de la acción teatral. Aunque los mecanismos presentados por Cervantes no son exclusivamente teatrales, sí nos ofrece un conflicto aprovechable, dramáticamente, por su universalidad. No encontramos extraño que un autor como Agustín Moreto, caracterizado por la meticulosidad de sus estructuras dramáticas, el análisis introspectivo de sus personajes, el control en el movimiento y ritmo de la comedia, así como en las abstracciones de la realidad, viera en el texto de Cervantes un material aprovechable para una adaptación dramática.

El texto cervantino, desde nuestro punto de vista, sigue unas determinadas fases cuyo planteamiento muestra de manera evidente el tema de la dialéctica existente entre el individuo y la sociedad, ejemplificándola en el caso de un joven licenciado cuya identidad se ve modificada por unas determinadas circunstancias (ya que el punto de partida de la historia de Vidriera es una

25 No es nuestro objetivo plantear las distintas aportaciones sobre la teatralidad, aspecto, por otra parte, todavía no resuelto por la teatrologfa. Sin embargo, es básica la consulta de KowZAN, TADEUSZ, Littérature et spectacle (Mouton/PWN, Varsovia 1975), ZICH, OTAKAR, Esthétique de l'art dramatique (Melantrich, Praga, 1931) y ALLEGR, LuIGI Teatro, spazio, società (Rebellato editore, Venezia, 1982).

26 Lotman,J. La structure du texte artistique, Gallimard, París) 1973, pg. 311. 
situación amorosa de rechazo) y cuya resolución es la incomprensión social respecto a esta individualidad. El Licenciado Vidriera cervantino es una especie de crónica de la formación de la conciencia de un personaje, una muestra del proceso de transformación de un personaje que adquiere conciencia de su singularidad y que sigue un esquema, más o menos, cíclico.

Decimos que este proceso es cíclico ya que comienza con una degradación espiritual (la ignorancia del joven Rodaja ${ }^{27}$ ), superada por el afán de conocimientos del personaje central (manifiesta en la itinerancia de su aprendizaje), que tiene su culminación en la nitidez mental que éste adquiere paradójicamente en su locura y finaliza con la degradación/decepción del mismo. De igual modo, el proceso individual de Tomás Rodaja va a conllevar un proceso social en el que la marginalidad de la locura es aceptada como tal pero rechazada con posterioridad por la propia sociedad y que Cervantes plantea así:

estudios $\rightarrow$ enfermedad $\rightarrow$ cambio de personalidad aceptada en su marginalidad $\rightarrow$ curación $\rightarrow$ cambio de personalidad rechazada socialmente $\rightarrow$ automarginación en la asimilación de una vida no deseada.

Por otra parte, a cada una de las secciones del proceso del personaje correspondería una técnica distinta: el aprendizaje de Rodaja es una narración con un esquema itinerante en un estilo descriptivo (del mismo modo sucede con la parte final), mientras que la parte central de la novela, donde hallamos la plasmación de un determinado didactismo, la configura una forma dialogada -diríamos que monologizada- donde Vidriera comenta con unos interlocutores, que tienen una mera funsión fática, sus puntos de vista referentes a cuestiones sociales en forma de apotegmas. Hasta aquí nos hallamos ante una forma prácticamente narrativa en el planteamiento cervantino.

Sin embargo hay ya materiales aprovechables dramáticamente. $\mathrm{El}$ punto de partida para el posterior desarrollo de la novela es un lance amoroso (una dama es rechazada por la apatía sentimental de un supuesto galán, de tal manera que ésta motivará la utilización de una pócima ocasionante de la locura del personaje), esta excusa sentimental, sin duda alguna, sería una buena base para un planteamiento teatral, $e$ incluso podría haber dado lugar a una comedia de magia o a una comedia cuyo inicio o artificio de la maraña fuera un hecho sobrenatural. Pero van a ser las características del personaje del licenciado las que van a suministrar el material dramático a Moreto que plantea un argumento muy diferente del cervantino ${ }^{28}$.

27 Algunos autores seffalan el parentesco del planteamiento cervantino del niffo Tomás Rodaja con el género picaresco, concretamente con el Lazarillo de Tormes. Ver el trabajo de RoDRIGUEZ LuIS, J. Novedad y ejemplo en las Novelas de Cervantes, Jose Porrúa, Madrid, 1980.

28 Carlos, noble de Urbino sin fortuna, regresa a su ciudad tras unos años de estudio en Bolonia. El motivo de su vuelta es el de reclamar una recompensa material por haber ayudado legalmente 
En una aproximación argumental de ambos textos encontramos concomitancias evidentes. Ambos personajes, Tomás y Carlos, han abandonado su ciudad para dedicarse al estudio de las leyes; ambos sufren un proceso de degradación cuyo punto central es la locura (Rodaja se cree loco y denuncia a la sociedad, Carlos se finge loco para poder denunciar la ingratitud que sufre) y su final va a ser semejante sin la negatividad de su toma de conciencia ante sus antagonistas. Sin embargo va a ser en la presentación del proceso de degradación del personaje central de la obra donde Moreto va a elaborar la adaptación del texto cervantino.

Hemos visto anteriormente cómo la temática amorosa va a ser el argumento principal de las comedias del XVII español, cuyo esquema básico es el de los obstáculos que deben superar los enamorados para conseguir llevar a buen término su amor. Aparentemente el argumento de El Licenciado Vidriera de Moreto es éste, sin embargo, pensamos que esta modelización no resulta operativa para el fin último que desprendemos del texto moretiano: una reflexión sobre la ingratitud humana en sus distintas facetas frente a la pureza o transparencia del individuo; sólo desde este planteamiento pensamos que Moreto se sirve de la excusa amorosa. Como afirma F. Casa ${ }^{29}$

To begin with, he needed a situation which could be used as the foundation upon which to build the theme. It is not at all suprising that he chose a love complication. The comedias which use this device are too numerous to mention for it is the favorite dramatic situation of the Golden Age

aunque pensamos que el tópico amoroso es modificado por el planteamiento de una situación política (que ningún estudioso menciona) considerada como un intento más de consecución de la fortuna por parte de Carlos y base real de la obra ya que ésta no existiría sin dicho planteamiento.

al duque a conseguir el gobiemo frente a los pretendientes rivales, Casandra y el conde Federico; de este modo podrá lograr la mano de Laura, a quien ama, ya que se vio obligado a dejar la ciudad instigado por las negativas del padre de la joven, Pompeyo, quien recomendó a Carlos la búsqueda de la fortuna. Sin embargo esta recompensa no llegará jamás porque Lisardo, amigo del licenciado, que intenta ascender socialmente y conseguir a Laura como esposa, traicionará su amistad.

A pesar de los méritos intelectuales y bélicos de Carlos, éste sólo encuentra en los demás constantes muestras de ingratitud. Ante la falta de sinceridad de sus falsos amigos, Carlos decide fingirse loco: hacer creer que es de vidrio y a traves de su locura recrimina el comportamiento de sus ofensores. Fracasa de nuevo pero como Licenciado Vidriera adquiere una fortuna considerable al ser aceptado como la diversión preferida de los cortesanos. Su nuevo fracaso le lleva a krecuperam la cordura y a acusar públicamente las injusticias de que ha sido objeto alcanzando el reconocimiento de sus méritos.

29 Op. cit. pg. 37. 
De este modo, mientras asistimos en el texto cervantino a la creación del personaje de Tomás Rodaja y su itinerancia pedagógica, Moreto nos presenta la fase final de un intento de consecución de la fortuna por parte de un personaje ya hecho. Así, nos hallamos ante un esquema

situación previa amorosa $\rightarrow$ consecución del prestigio que no de la fortuna $\rightarrow$ situación política como posible solución de la situación amorosa que contradice el modelo lopesco de obra sentimental pero que va a servir a Moreto para exprimir cada uno de los caracteres que aparecerán en su texto y especialmente la ingenuidad del personaje principal, muy cercano al cervantino, y los pasos del proceso de su desengaño.

Ambos «licenciados» tienen características comunes:

1) La voluntad de narrar un episodio cíclico que va de la esperanza (en el caso de Rodaja, de alcanzar un grado elevado de reconocimiento intelectual, en el de Carlos el de la consecución de la fortuna material) al desengaño ante el comportamiento social (en Rueda, la marginación de que es objeto como intelectual, en Carlos el desengaño ante sus amigos). Pensamos que ambas obras tienen un final negativo ya que no se ha logrado el reconocimiento de ambos personajes, a pesar del desenlace feliz del texto dramático.

2) La voluntad de ejemplificación que en ambos autores va de lo individual a lo general. Tanto Rueda como Carlos son individuos que se enfrentan a la sociedad como casos particulares; sin embargo, en el trasfondo encontramos una universalización del sentimiento del desengaño ante una colectividad que no reconoce los valores inmanentes a la persona, independientemente de su condición. En ambos casos va a ser la transparencia e ingenuidad de los personajes las que van a provocar el choque entre los dos espacios en conflicto.

En el caso de Moreto ambos puntos van a concentrarse en un tema central del Barroco, la Fortuna ${ }^{30}$. También aquí asistiremos al mismo procedimiento universalizador, reflejado en las tipologías del sentimiento de la ingratitud:

a) La ingratitud del amor (universal): el desprecio de Laura a causa de la obediencia al padre (individual);

b) La injusticia inconsciente (universal): la enajenación amorosa del duque de Urbino y de Casandra (individual);

30 El tema de la Fortuna es expuesto por Moreto a través de las acciones que acontecen a la pareja protagonista, Carlos y su criado Gerundio. Ni uno ni otro se corresponden a los prototipos del galán y gracioso lopescos de manera exacta: Gerundio es, en cierto modo, la conciencia de Carlos sufriendo lo mismo que éste pero pronunciando palabras que, en la logica dramática, corresponden a su seffor; se produce un desdoblamiento en Gerundio de la personalidad del joven licenciado. No vamos a extendernos al respecto ya que este tema merece un trabajo aparte dado su extraordinario interés. 
c) la ingratitud de Pompeyo (individual) por el interés material (universal) y

d) la amistad traicionada (universal): Lisardo (individual).

Si en El Parecido en la corte la referencia obligada era la figura de Lope de Vega, en El Licenciado Vidriera asistimos a unos planteamientos absolutamente calderonianos ya que Agustín Moreto va a utilizar una imagen o una metáfora que va a conducir al lector/espectador hacia la intuición básica de la obra: en este caso, la imagen es absolutamente referencial ya que el espectador conoce la novela cervantina y va a asimilar su ejemplaridad. Así pues, la imagen de El Licenciado Vidriera va a verse reflejada dramáticamente en la configuración del personaje $e^{31}$ y, del mismo modo, la metáfora va a adquirir una forma tangible en escena formando parte de la acción (en el momento en que Carlos se finge loco) y utilizando Moreto variaciones que tienen el sentido de la imagen dominante (cada uno de los pasos del desengaño del licenciado).

Moreto va a utilizar técnicas calderonianas en el tratamiento de la imagen de la transparencia pero también en el sentido de que va a intentar convencernos de que el desarrollo de la obra se establece por un proceso racional y que la idea que plasma en el texto puede ser, literalmente, cierta. Podemos aplicar a Moreto las palabras que A.A. Parker dedica a Calderón ${ }^{32}$

Calderón, therefore, follows the principle already exemplified in the best plays of Lope de Vega: that unity, which is essential to all art, is found in drama not in unity of plot and action, as the neoclassicist were later to insist, but in unity of theme. A play's theme can have many facets and several can be illustrated in the single theme, illustrated by comparison or by contrast

Una unidad total y coherente en la construcción dramática (que podemos hacer extensible a la novela de Cervantes ${ }^{33}$ ) donde la unidad de la acción depende de la unidad del tema sin que se excluyan dos o más historias dramatizadas en una conexión causal.

Si concluíamos el apartado de El Parecido en la corte constatando el hecho del trabajo de re-fundición de Moreto respecto a los textos de Cervantes y Tirso, en el caso de El Licenciado Vidriera hemos de referirnos al trabajo de re-creación dramática de un texto de otro género.

31 Ver al respecto el estudio de A.A. PARKER, The mind and art of Calderón, Cambridge UP, 1988.

32 Op. cit. pg. 19.

33 Es interesante la consulta del trabajo de A. SÁNCHEZ, Reminiscencias cervantinas en el teatro de Calderón, Anales Cervantinos VI, 1957, pp. 262-270. 
Pensamos, finalmente, que el fenómeno de las llamadas «obras no originales» de Moreto necesitan de una formalización metodológica que aprecie sus valores estéticos y hacerse extensible a los mecanismos diversos de escritura dramática que se desarrollaron en el siglo XVII español. 